The Journal of Academic Librarianship, vol. 19, no. 2, p. 68-71

C1993 by the Journal of Academic Librarianship.

http://www.elsevier.com/wps/find/journaldescription.cws_home/620207/description\#description

\title{
Acquisition of CD-ROM Databases for Local Area Networks
}

\section{Trisha L. Davis}

Head, Continuation Acquisition Division,

Ohio State University Libraries,

Columbus, $\mathrm{OH}$.

The acquisition of CD-ROM products for the local area network environment presents several new challenges to the acquisitions function. Subscription and pricing options vary widely, licensing issues complicate and extend the order process, and the library's local area network application must be clearly understood and defined. The author presents an analysis of these issues as they impact the role of the acquisition librarian.

To provide expanded information access services to patrons, academic libraries are experimenting with a wide variety of database and network options. A remarkably popular option is the CD-ROM network, a local area network (LAN) that provides simultaneous multipatron access to multiple CD-ROM databases. This innovative marriage of LAN technology and CD-ROM products has raised new questions of hardware and software compatibility, database coverage, and network licensing. It also has provided the opportunity for the acquisition librarian to develop a new role that links collection development, technical services, and CDROM publishers.

In the CD-ROM network planning and implementation process, the unique expertise of the automation librarian, the collection development librarian, and the acquisition librarian are truly complementary. The automation librarian's experience with microcomputers, CD-ROM drives, CD-ROM stand-alone applications, and networking software provides the technical support for the network. The collection development librarian's skills in discovering, investigating, and evaluating new products provides direction in exploring hundreds of databases, many with overlapping content and coverage. The acquisition librarian's skills are useful in establishing vendor relationships, understanding product pricing options, obtaining test databases, and negotiating license agreements for network applications.

This article addresses the distinctive factors involved in the acquisition of CD-ROM databases for a local area network. The discussion is based on an examination of more than 20 CD-ROM titles considered for two LANs at the Ohio State University (OSU) Libraries. (See Table 1). The analysis has revealed unusual considerations that affect every aspect of the acquisition function.

This article also examines how acquiring CD products may lead to new areas of responsibility for the acquisition librarian. By researching product availability, acquiring sample databases for testing, and negotiating license options, acquisition librarians can expand their role to provide valuable services in the planning and implementation of these networks. The impact of these expanded responsibilities will be stressed throughout the article. 


\begin{tabular}{|ll|}
\hline Table 1 & \\
CD-ROM Products Examined for LAN Use \\
\\
\hline \\
Product & \\
& Publisher/Vendor \\
Agricola & \\
Applied Science \& Technology Index & SilverPlatter \\
Biography Index & H.W. Wilson \\
Biological Abstracts & H.W. Wilson \\
Book Review Digest & SilverPlatter \\
Business Periodicals Index & H.W. Wilson \\
Current Contents & H.W. Wilson \\
& Institute for \\
Dissertation Abstracts & Scientific Information \\
& University Microfilms \\
Electronic Encyclopedia & International \\
& Grolier Electronic \\
ERIC & Publishing \\
Essay and General Literature Index & SilverPlatter \\
Expanded Academic Index & H.W. Wilson \\
Facts On File & Information Access Corp. \\
Humanities Index & Facts On File \\
Library of Congress Subject Headings & H.W. Wilson \\
Microsoft Bookshelf & Library of Congress \\
MLA International Bibliography & Microsoft Corp. \\
Newspaper Abstracts & H.W. Wilson \\
PAIS & University Microfilms \\
PsycLIT & International \\
Readers' Guide Abstracts & SilverPlatter \\
Science and Technology Reference Set & SilverPlatter \\
Social Sciences Index & H.W. Wilson \\
Sociofile & McGraw-Hill \\
Statistical Masterfile & H.W. Wilson \\
& SilverPlatter \\
& Congressional \\
& Information Service \\
\hline
\end{tabular}

\section{Historical Development of CD-ROM Acquisitions}

In the 1980s, the selection and acquisition of CD-ROM databases appeared to fall into a traditional pattern. The first CD-ROM databases were often user-friendly computer-enhanced versions of popular print products well known to the selection staff. CD-ROM database acquisition focused on two major issues: funding and product evaluation. Libraries were concerned primarily with establishing funding mechanisms to cover the initial capital costs of the hardware while maintaining adequate budgets to cover both the database subscriptions and the traditional print subscriptions. ${ }^{1}$ As the technology gained popularity, additional funding was needed to acquire multiple copies of heavily used databases. While short-term funding options had provided the means to acquire the hardware and establish this highly popular service, longterm solutions were needed to guarantee ongoing support.

Once the funding was secured, selection and acquisition of specific databases were often frustrated by compatibility problems with existing hardware equipment. ${ }^{2}$ Technical standards for hardware configurations and various retrieval software packages were still under development. Microcomputers and peripheral equipment purchased with funds for a specific application often had to be adapted for use with other databases.

The goal of integrating the ordering, receipt, and control of CD-ROMs into normal operations appeared to be quite reasonable provided adequate resources were available. The professional literature provided an abundant supply of advice on CD-ROM evaluation and selection. Questions about standardization, collection development, budget implications, and end-user training were addressed thoroughly. ${ }^{3}$ A variety of printed directories, journals, and newsletters dealing specifically with CD-ROM products were available to provide both descriptive information and product reviews. ${ }^{4}$ Monthly advertisements in widely read journals 
such as American Libraries and Library Journal implied that librarians could get products for any application with just a simple toll-free telephone call. Given this array of readily available information, it was easy to assume that the acquisition issues for $\mathrm{CD}$ products would be straightforward.

As CD-ROM applications and usage increased, however, the limitations of the singleuser workstation became more apparent. Due to the enormous popularity of the technology, patrons were no longer able to use CD products at will, and many libraries were forced to schedule usage. Products issued on multiple discs became increasingly difficult to use. Libraries began to develop local area networks that could provide simultaneous multi-user access to individual CD-ROMs.

In this context, the acquisition function for $\mathrm{CD}$ products has taken on new significance. Some library vendors are not authorized to handle CD-ROM network applications or licensing. CD-ROM producers and distributors have established their own unique subscription arrangements and often are not prepared to deal with the library's individual network needs. Before products can be acquired, special license agreements to meet the local library's network application have to be negotiated. To provide these services, the acquisition librarian must thoroughly understand the CD-ROM network technology, establish new vendor relationships, explore unconventional purchasing options, and modify local policies and procedures to integrate the processing of this new format into daily operations.

\section{The Challenge of Database Selection}

At first consideration, the selection and acquisition of CD-ROM databases may seem to fit into established library activities. The network hardware and software parameters are established by the automation librarian; the choice of databases is narrowed by collection development librarians and guided by collection strengths and patron demands. Upon closer examination, however, it quickly becomes clear that a request for a given CD-ROM title may involve questions of coverage, choices of publication patterns, and subscription options that must be resolved. Acquisition librarians cannot always rely on traditional selection routines in making these types of decisions; and they may find it difficult to readily incorporate new acquisition activities into existing procedures.

There is little, if any, standardization of coverage among the publishers or the products they develop. The typical CD-ROM database is not produced or distributed in parallel with the publication pattern of the related print product. Rather, it may be issued with a choice of coverage dates, offered as a complete set, or available with variant purchase or lease options. A database may be offered as either a monthly or quarterly subscription, with a considerable difference in pricing. The current year subscription may include a specified backfile on the same disc, or, backfiles may be available only as a separate subscription. A subscription may cover the current year plus the last two years' backfiles, requiring the library to either return a disc each time the first disc of the new calendar year is received, or pay an extra fee to retain the disc.

Publication patterns, the number of discs, and the content of discs may vary widely within a single subscription. This may not be of concern when ordering a stand-alone product designed to supplement or enhance existing resources. The number of discs required to support a given database may not impact its selection or use. In the CD-ROM network scenario, however, information on the availability and content coverage of the database could be a deciding factor in selection - afterall, library network capacity is finite. The addition of discs to an established subscription could limit the total number of database products the network hardware can support. 
A review of CD-ROM products will also reveal a broad spectrum of subscription prices and purchase options. Some products are available on subscription at a set price, with preestablished backfile coverage automatically included in the package. Some subscriptions only cover the most current two or three years, requiring the library to pay annual price increases to retain coverage.

Some publishers allow subscribers to acquire additional backfiles separately from the continuation subscription through a one-time purchase of an archival set - an option that permits more flexibility in meeting network coverage. However, publishers may charge an annual fee to continue the software license and customer support of these backfiles if the library does not maintain a current subscription. For example, subscribers may have to return previous versions of the CD-ROM disc and accompanying software whenever they receive the latest disc from the publisher. If the library does not renew its subscription, it may keep only the latest version of the disc and software, and no ongoing technical support will be provided.

Publishers may divide their databases into volumes, based on chronological coverage, or editions, based on subject or geographical groupings. This option allows for separate pricing per disc, a cost savings for libraries who may not be interested in or able to afford the complete set. These options may or may not coordinate with the library's current coverage in print or the intended coverage of the CD-ROM network.

A clear understanding of these subscription and pricing options often requires extensive conversations with database vendors. Acquisition librarians must take an active role in distinguishing the various options available to assure that proper coverage decisions are made and that technical resources are adequate to support the files.

\section{The Ordering Process}

Ordering CD-ROM products often requires special attention from the acquisition librarian. The order request for a CD-ROM database must designate the exact version of the product, the correct subscription options, and the appropriate license agreement. Even the major vendors do not have consistent order requirements across products lines. Correct product description or subscription period may be available only from the database producer. An order may include handling arrangements for test products, custom software applications, partial shipments, and record-keeping for items that must be returned.

The automation librarian may express interest in a variety of peripheral products that support the databases. Although available, sometimes these items must be purchased separately from the database and sometimes they are difficult to find. Acquiring the producer's in-house installation and support manuals, testing unreleased software updates, and having networkspecific modifications made may be critical to the success of a database. From a public service perspective, the availability and acquisition of templates, keycaps, instructional brochures, training videos, and other point-of-use materials may save hours of instructional support.

Pricing arrangements for CD-ROM databases vary widely. The advertised price of a given product may not reflect added charges or possible discount arrangements that the acquisition librarian can unearth in researching the order request. A significant price variable is the frequency of updates, with the cost differential stipulated in the subscription rates or hidden in variable shipping charges. Discounts are often available for second and subsequent orders shipped to the same address or to subscribers of an associated journal, a related database, or the equivalent print product. The acquisition librarian can investigate these options and work with the supplier to provide the optimum pricing arrangement for the library's specific needs. 


\section{The Question of Network Licensing}

Publishers currently market their products with a standard single-user/singlemicrocomputer license. Usually the license is simply included in the compact disc or system software packaging and becomes effective when the item is opened. Some publishers, such as Bowker Electronic Publishing, take a more proactive approach and require a signed license agreement on file for each institution. Bowker's agreement specifically prohibits the move or transfer of the product from the "licensed location" without prior written consent. Such an agreement prohibits use of the database or software on a multi-user network system under any circumstances. In this situation, negotiation for an institution-specific license is the only solution.

The basic move from a single-user CD-ROM stand-alone application to a multiple-user CD-ROM network requires specific site license agreements from most publishers. The request for campus-wide access beyond the single-building network presents a second level of licensing concern. Both CD-ROM publishers and information providers see in this level of access the potential for copyright abuse. ${ }^{5}$ Even when CD-ROMs are advertised for "network application," license restrictions may preclude their use on some libraries' local area networks.

Our experience with the local area network licensing at OSU Libraries yielded four areas of possible difficulty. First, a few publishers simply do not address the issue of network access and are loathe to discuss it. Their desire to protect a similar print or online product appears to be the primary sticking point. We have had mixed results in trying to negotiate licensing with such publishers. In one case, the publisher agreed to allow network testing with licensing terms and fees to be determined at a later date. In another situation, the publisher preferred that we purchase multiple copies of the database to run simultaneously on the network.

A second area of potential difficulty is the definition of users. While few publishers would question the status of a library patron using a print resource, some publishers are stipulating in their license agreements who can use their electronic resources. In our case, sophisticated network software allows us to limit remote access to OSU faculty, students, and staff and to track use through authorization codes and passwords. In limiting remote access by patron type, however, some of these agreements also restrict access for the casual user at the libraries' public area workstations - a limitation that is undesirable and impractical from the library's vantage. We have found that a successful response to such a requirement is to work with the publisher to assure quality control of remote access in exchange for normal levels of in-house workstation access.

A third difficulty in network negotiations is agreement on what constitutes the physical network - that is, the buildings in which the network resides. Several vendors' fee structures actually penalize those whose systems allow multiple-site access. One vendor's standard local area network agreement restricts use of the CD-ROM software to a single LAN housed within one building. This approach allows unlimited access at dedicated workstations, and thus supports a centralized library system; but given the demonstrated fact that most CD-ROMs cannot support more that four to six simultaneous users without significantly degraded response times, the "unlimited users" allowance may be of limited value.

License agreements that restrict use to a single building will not support terminals in OSU's Undergraduate Library, which is separate from the Main Library, and such products have not been included in the OSU network. OSU Libraries' approach to such policies has been to upgrade the license agreement through purchase of additional access for patrons at external sites. 
The final, and perhaps most serious, difficulty is remote access. Each CD-ROM local area network defines itself through a complex system of options. A typical network may include dedicated terminals or workstations, dial-in workstations that also function as standalone microcomputers, or dial-access capability from other campus networks or from home computers. To allow multiple-site dedicated access but not dial access further restricts the network configuration.

H.W. Wilson's first LAN policy was restricted to a single site with unlimited access within that building. To accommodate all sites of the OSU Libraries, Wilson originally charged an additional 10 percent of the annual subscription fee per external port per database. Thus, providing users in other library buildings with access to the complete network on four external ports used to cost OSU Libraries an additional 40 percent a year. Wilson has since dropped all charges for additional ports and now includes backfiles in all subscriptions. Other database producers are not as progressive and build in complex fees based on number of users or workstations. The library involved in negotiating such issues must carefully weigh the network configuration requirements against simultaneous user fees - and purchase no more access than the system can successfully support.

\section{Final Observations}

For the automation librarian, the challenge of the 1990s will be to predict which of the new CD-ROM LAN systems will provide stable hardware, will be backed by reliable service, and will be flexible enough to support a wide range of database products. ${ }^{6}$ For the collection development librarian, the challenge will be to wade through the hundreds of products available and determine which will best fill users' needs. For the acquisition librarian, an equal challenge will be to identify those CD-ROM producers and distributors who are willing to provide compatible products, reasonable multi-user license fees, understandable lease agreements, and reliable service.

As the marketplace of CD-ROM products and services continues to expand and change daily, keeping abreast of product availability, pricing, and licensing issues is a crucial task. At OSU the acquisition librarian's role in gathering information on the CD-ROM products for selection decisions, establishing subscriptions, and negotiating license agreements has proven to be challenging, productive, and rewarding.

\section{References}

${ }^{1}$ John Cochenour, and Pahicia Weaver-Meyers, "CD-ROM: Practical Considerations for Libraries," Journal of Library Administration 9 (No. 3, 1988): 57-67.

${ }^{2}$ David Raitt, "Evaluating CD-ROMs: An Observational Perspective," in Proceedings, 1989: National Online Meeting, ed. Carol Nixon and Lauree Padgett (Medford, NJ: Learned Information, Inc., 1990), pp. 343-353.

${ }^{3}$ Marie Kascus and Faith Merriman, "CDROM: Compact Discs in the Library," Collection Management 10 (Nos. 3/4, 1988): 181-189.

${ }^{4}$ Paul Travis Nicholls, "A Buyer's Guide to CD-ROM Selection: CD-ROM Product Directories and Review Tools," CD-ROM Professional 3 (May 1990): 13-21.

${ }^{5}$ Christopher G. Pooley, "CD-ROM Licensing Issues," in CD-ROM Licensing and Copyright Issues for Libraries (Westport, CT: Meckler, 1990), pp. 31-43.

${ }^{6}$ Edwin M. Perry, "The Ezekiel Effect - Factors Affecting Development of Local Area Networks for CD-ROM," Laserdisk Professional 3 (January 1990): 7-9. 